\title{
Elegies to Cinematography: The Digital Workflow, Digital Naturalism and Recent Best Cinematography Oscars
}

\author{
Jamie Clarke
}

Southampton Solent University

\begin{abstract}
Introduction
In 2013, the magazine Blouinartinfo.com interviewed Christopher Doyle, the firebrand cinematographer renowned for his lusciously visualised collaborations with Wong Kar Wai. Asked about the recent award of the best cinematography Oscar to Claudio Miranda's work on Life of Pi (2012), Doyle's response indicates that the idea of collegiate collaboration within the cinematographic community might have been overstated. Here is Doyle:
\end{abstract}

Okay. I'm trying to work out how to say this most politely ... I'm sure he's a wonderful guy ... but since 97 per cent of the film is not under his control, what the fuck are you talking about cinematography ... I think it's a fucking insult to cinematography ... The award is given to the technicians ... it's not to the cinematographer ... If it were me ...

How to cite this book chapter:

Clarke, J. 2017. Elegies to Cinematography: The Digital Workflow, Digital Naturalism and Recent Best Cinematography Oscars. In: Graham, J. and Gandini, A. (eds.). Collaborative Production in the Creative Industries. Pp. 105-123. London: University of Westminster Press. DOI: https://doi.org/10.16997/book4.g. License: CC-BY-NC-ND 4.0 
I wouldn't even turn up. Because sorry, cinematography? Really? (Cited in Gaskin, 2013)

Irrespective of the technicolor language, Doyle's position appeals to a traditional and romantic view of cinematography. This position views the look of film as conceived in the exclusive monogamy the cinematographer has historically enjoyed on-set with the director during principal photography. Alternatively, the digital workflow in special effects-heavy, 3D extravaganzas such as Life of $P i$ has caused the director's allegiances to wander to the back-end of the production process where no-collar digital hipsters finalise the look of the film at their workstations. Championed elsewhere, by the likes of Richard Florida (2012), as constituting a new creative class characterised by tolerance, talent and technology, Angela McRobbie points to the paradoxes of this 'hipster economy' (McRobbie, 2016, p. 50). For McRobbie, this model is nothing less than a wholesale attempt to rewire the priorities of a new generation of workers. Following the fieldwork of Andrew Ross's No-Collar: The Humane Workplace and its Hidden Costs (2004) that investigated the workers at the digital media company Razorfish in New York, McRobbie's argues that surface style is a palliative for the precarious, informal and casualised working conditions that characterise the sector. Correspondingly, whilst Doyle bewailed the promiscuous origins of Life of Pi, digital effects workers themselves were also unhappy with the new ménage à trois between themselves, the cinematographer and the director. As the ancien régime was bunkered inside the Dolby Theatre, outside, representatives of Rhythm and Hues (the team responsible for the visual effects on Life of $\mathrm{Pi}$ ) threatened to storm the citadel protesting Hollywood's 'race to the bottom' following the announcement ten days earlier that their company were laying off over 200 workers (see Curtin \& Vanderhoef, 2015, pp. 219-220).

These events hence provide a mise en scène of the struggle for supremacy over the filmic look since the ascent of the digital workflow that displaced the cinematographer's status whilst failing to safeguard that of the insurgents. The 2013 ceremony was merely the crescendo of this particular hoo-ha whereby the best cinematography Oscar had previously been awarded to a series of CGIintensive spectacles, with authority over the look increasingly scattered across the workflow and outsourced overseas. The controversy began in 2009 with the Academy's recognition of Mauro Fiore's work on Avatar (2009), a film with extensive pre-visualisation having taken place before Fiore's arrival to the team in New Zealand, and with much of the cartoony aesthetic having been accomplished in Los Angeles by Twentieth Century Fox's in-house digital design team, Lightstorm. Since Avatar, the Oscar has subsequently been awarded to similarly effects-freighted work: Wally Pfister's work on Inception (2010); Robert Richardson's on Hugo (2011); Claudio Miranda's on Life of Pi and Emmanuel Lubezki's on Gravity (2013). The look of digital film, so the argument runs, is now illegitimately conceived long after image capture and the departure of the cinematographer in the dark corners of the visual effects department. 
Technological change is here leveraged as a profit-seeking and costs-reducing mechanism that challenges established hierarchies, redefines job descriptions and may well be contributing to the end of what was once called the cinematographer, perceived now as an expensive luxury in this new globally mobile and digitally supple production culture.

This chapter investigates these developments. I begin with a review of the recent critical attention allocated to the cinematographer. From here, the essay introduces the main features of the digital workflow that I read principally through the optics of production studies as advocated by the work of John Caldwell. The article culminates with an analysis of the candidates for the best cinematography Oscar in 2015. As indicated in this introduction, I view the Oscar ceremony as a site where such labour positions are packaged for public reception, contested and fought out.

\section{Collaborative partnerships}

One irony in these developments is that the role of the cinematographer has only recently begun to seriously receive critical attention. Richard Misek provides the following classical definition of cinematography as presented by The American Society of Cinematographers (ASC):

The ASC's view of film production can be summarized as follows: a film's director has a mental image (a "vision") of how the script will appear on screen; the DoP [or cinematographer] realizes this "vision" by registering moving images with a "look" that corresponds to, or improves on, what the director imagined (Misek, 2010, p. 405)

This understanding sees the workflow as originating with the director's seedling vision. The labour involved in giving birth to this vision however requires the cinematographer who acts as an essential handmaiden positioning the collaborative act as a consummation uniting the two roles in keeping with the ASC's motto: 'Loyalty, Progress, Art' (cited in Keating, 2010, p. 16). The ASC motto hence carefully positions seniority-based hierarchy and linear workflow as the foundational rock on which art is built. In the literature emerging since 2010, the cinematographer remains loyal and deferential however 'collaboration' has emerged as a watchword that suggests a more equal role with the director. Symptomatic of this trend is Christopher Beach's A Hidden History of Film Style: Cinematographers, Directors and the Collaborative Process (2015). Beach's volume is structured around a series of case studies whereby frequent directorcinematographer collaborations are documented from D.W. Griffith and G.W. 'Billy' Bitzer to Oliver Stone and Robert Richardson. If the case studies serve to highlight classic director auteurs on the one hand, then the ambition of the book on the other is to widen the attribution of credit beyond a solitary vision- 
ary genius and towards the collaborative photochemistry within partnerships seen to midwife the look. Ultimately however, Beach's radicalism proves to be rather more modest and can be reductively summarised as the assumption that behind every good director is (or at least was) a good cinematographer. As such Beach's position seems anxious to ring-fence the director-cinematographer axis, something that more 'meta' approaches to auteur studies have been anxious to deconstruct (See here Gerstner and Staiger, 2003 and Wexman, 2003). Arguably this discourse on director - cinematographer collaboration seems elegiac in its soft-focus longing for a less turbulent, analogue era where everyone supposedly knew their place and when directors were simply directors and cinematographers were simply cinematographers.

What is perhaps new in the reheating of this auteur debate is the attempt to nudge the cinematographer into the light. It is perhaps no coincidence that a commonplace in the revisionism is the relationship between Orson Welles and his cinematographer on Citizen Kane (1941), Gregg Tolland. Tolland's work features extensively in the work of Patrick Keating (see Keating, 2010, pp. 231-7), is afforded a chapter in the work of Beach (see Beach, 2015, pp. 55-85) and preoccupies an article by Philip Cowan (2012). Cowan, for instance, follows the 'whodunit' narrative of auteurism by attributing Kane's deep focus and staging-in-depth innovations to the experienced Tolland rather than his brief encounter with the ingénue, 26-year-old radio impresario (see Cowan, 2012, pp. 77-8). No doubt the frequency of references to Kane is strategic given its centrality in the annals of film reception, but it is then perhaps reception that is key to understanding auteur criticism more generally. Tim Corrigan (1990) similarly draws attention to how auteur discourse is not so much a phenomenon of production as reception. For Corrigan, auteurism consolidates meaning for audiences and provides a shorthand for quality that can subsequently be leveraged in marketing. That the discourse of auteurism seems shot through with the chivalric language of romance, conquests and elegiac longing for origin myths is perhaps because it is always already packaged as a publicity narrative geared toward reception. Disregarding the accuracy of Cowan's thesis (and it is certainly convincing as a piece of historical revisionism) what interests this discussion is precisely why this flurry of attention surrounding the cinematographer should appear now.

I want to view 'collaboration' as an unstable term that acknowledges the potential for disruption over the control of the filmic look whilst attempting to defuse this instability. Precisely because they are today only one part in a more cluttered digital workflow, the cinematographer requires intensified external affirmation to consolidate their now precarious position and moreover is prepared to stimulate this affirmation via a series of discursive tactics. The sudden intensification of references to the cinematographer as collaborator sine qua non is a symptom of this stabilisation strategy. The case studies discussed above are therefore, I argue, as much about the contemporary status of the cinematographer as they are about the historical and romantic figure of the 
cinematographer that they invoke. It is arguably no coincidence therefore that two of the critics spearheading the critical attention to cinematography, Keating and Cowan, are themselves practicing cinematographers. Ultimately, the digital landscape of globally networked production, elsewhere celebrated for increasing democratic access to the production workflow, is the self-same trigger for increasing competition over who authors the look of the film.

\section{Producing the 'Cinematographer'}

The controversy surrounding the attribution of credit is, of course, not merely aesthetic but also materialist. As John Caldwell illustrates in his path-breaking work on production cultures, such controversies are perhaps best understood in terms of prestige and particularly job security and remuneration (see Caldwell, 2008, 2013, 2014). The positioning of the cinematographer as central collaborator can be viewed as the discursive product of stakeholders who themselves helped to produce a romantic idea of 'cinematography'. Critical here was the anxiety to move away from a mechanical gear-grinding view of practice to something more akin to a labour of love. This understanding is consistent with Keating's historical account that, beyond a merely formal poetic approach, wraps style within an institutional and discursive mainframe. Keating thus investigates the role played by the ASC and its journal American Cinematographer in crafting an 'idealised' view of the cinematographer for reception (Keating, 2010, p. 17). Chartered in 1919, the ASC and its trade journal American Cinematographer (first published in 1920) lobbied for the elevation of cinematography to the status where the energies circulating on set were condensed into a particular figure who might merit recognition by a further valorisation mechanism: the Oscar ceremony. According to Keating, the ASC initially promoted an assertively aesthetic style during the silent period and especially between 1922 and 1927, with cinematography then 'designed to be noticed' (Keating, 2010, p. 28). Precisely because the cinematographer did not yet exist as such, assertive style was leveraged to generate attention. As Keating demonstrates, the ASC deliberately redefined the role away from a functionary following orders, towards that of an aesthete who was an arguably an equal collaborator with the director. As Keating summarises:

The cinematographer had acquired a new public identity. He had come to be perceived as a person with good taste [and] emotional sensitivity ... the ASC crafted a compelling narrative about the development of a new kind of art - and a new kind of artist. No longer a laborer turning a crank, the cinematographer was a skilled professional making a valuable contribution to the cinema - a contribution that could best be described as aesthetic (Keating, 2010, pp. 15-16) 
The key phrase here is 'come to be perceived as a person'. Once the look of film was allocated an aesthetic sensibility, the popular understanding of art required that an individual should be seen as author of this look. Counterintuitively, it is not so much artists that produce great works but rather great works that produce artists. Downstream, this ability to 'to be perceived as a person' organises industrial contractual relationships. The films industry's division of labour is administered by the separation of workers as below-theline (BTL) and above-the-line (ATL). This system has historically seen ATL roles within the production process individually rewarded via handsome residuals rather than the comparatively minor collective residuals (such as pension and health care entitlements) received by BTL interchangeable contributors (see Stahl, 2009, pp. 54-68). The closure of the silent period saw the elevation of the cinematographer from the anonymity of the crew's BTL ranks into an individual person who was eligible for ATL benefits. It is not coincidental this period sees the first Oscar awarded to individual cinematographers, with the first statuette awarded in 1927-8. Viewed through this wider-angle lens, the surge in academic discourse testifying to the significance of individual cinematographer's contributions seems less a sign that the cinematographer's time has finally come. Instead, the sudden heat surrounding 'painters with light' can be interpreted as a response to the increasing destabilisation wrought by the digital workflow and the subsequent intensification of the personal branding strategies of cinematographers and their entourages.

\section{The digital workflow}

Clearly, these materialist concerns are the forcefield that structures the supposedly more rarefied and refined discourse of cinematographer as the disinterested auteur documented above. The romantic view of the cinematographer's craft as happily collaborative is synchronous with a specific technological moment that has now perhaps passed. This discursive formation lasted from the silent period to the rise of digital and as Richard Misek states stems from, 'the limitations of photochemical postproduction technology' (Misek, 2010, p. 405). Nevertheless, the cinematographer would largely oversee these limitations. As discussed by Stephen Prince, during the photochemical period, the look would be controlled organically on-set via production design, the selection of a particular stock with inherent image characteristics, through the manipulation of natural or artificial light sources and in-camera through exposure adjustments (see Prince, 2004, p. 26). In postproduction, colour timing tactics (such as flashing, pushing, bleach bypass and cross-processing the negative) could make adjustments to contrast and colour but such processes were limited to the entire image, again, following the cinematographer's instructions in the laboratory. Colour timing was hence capable of only primary correction 
(where the entire image is altered) because attempts to change exposure would inevitably effect colour and vice versa. As Misek concludes, "the "look" of a photochemical film is indeed primarily dependent on choices made when filming' (Misek, 2010, p. 405). This situation is now a thing of the past as digital grading allows for secondary colour and contrast correction via the application of, for instance, masks enabling specific parts and specific qualities of the image to be warped. Commentators point here to O Brother, Where Art Thou? (2000), photographed by Roger Deakins for the Coen brothers, as a landmark film the first to be scanned and digitised in its entirety (see Prince, 2004, p. 28). Secondary digital grading here allowed the postproduction team to isolate and de-saturate the lush-green footage captured during the Mississippi Summer to evoke the Dustbowl 1930s photorealism of the Farm Security Administration. This process cracked open the filmic look, allowing local chroma and luma alteration by insurgent contributors with alternative, now digital, skillsets. The possibility to effectively re-shoot the film in postproduction meant that the role of the cinematographer was also redrawn. As Caldwell points out of these developments:

Distinctions have been leveled, workflow is no longer linear and lockstep (with discrete, successive stages), and artistic responsibility has been re-delegated and dispersed across the porous boundaries that once defined the production and postproduction process. (Caldwell, 2008, pp. 183-4)

As such, Caldwell provides a labour-inflected twist to these technological developments investigating the fallout on craft relationships scrambled by the digital workflow. New roles have hence flooded into this process, including the digital colorist, the digital intermediate technician, and the visual effects supervisor. The transition to digital bloats a now distended and non-linear workflow, intensifies competition and undoubtedly downgrades the hard won status of the cinematographer. As Caldwell states:

The best way to study BTL authorship is not to look for some essential BTL authorial trait or profile but to look at each production as a dynamic process involving tensions and struggles between "strategic" ATL "control schemes" and "tactical" BTL "counter-measures" (Caldwell, 2013, p. 361)

The ultimate implication is that collegiate discourses of who is the principle collaborator occlude a battle for survival whereby industry craft-workers operate as entrepreneurs deploying an arsenal of promotional technologies of the self to consolidate their role within the new production ecology. It is in this context that I understand the 2015 nominees for the best cinematography Oscar. 


\section{The 2015 Oscars}

The Academy of Motion Pictures Arts and Sciences was chartered on 4 May 1927 and, according to John Atkinson's history of the Oscars, was 'something between a union and a marketing organisation' (Atkinson, 2001, p. 8). Since its inception in 1929, the Academy's Oscar ceremony has therefore operated not merely to, in the Academy's works, 'honor outstanding achievement' but as a shop window for industry practices and workflows. The impact of an Oscar victory are difficult to calibrate due to the number of variables involved, however the successful can expect to enjoy a surge in box office receipts following nomination and a further kick following an individual win. For instance, Danny Boyle's Slumdog Millionaire (2009) earned 30 per cent of its take following its nomination and a further 30 per cent following its victory in the best picture category (see Buckley, 2014). The voting system for individual categories is byzantine (operating according to a variation on the single transferable vote model) but significantly academy members eligible to vote in any given category are, according to Gehrlein and Kehr, 'associated with the specialization of the category' (Gehrlein and Kher, 2004, p. 227). Hence the shortlist for any category designates a form of peer recognition whilst simultaneously providing a mechanism whereby a particular craft is able to manage an ideal self-representation for public reception. The publicity extends beyond the high-profile acting categories and also affects the crew. As Peter Bart, editor of Variety, indicates, 'Without question, the Oscar has a great effect on behind-the-scenes people ... if for no other reason that they come into the spotlight for the first time in their careers' (cited in Goodale, 2004).

The nominees for the best cinematography Oscar in 2015 were Dick Pope for his work on Mr. Turner; Robert Yeoman for lensing The Grand Budapest Hotel; Lukasz Zal and Ryszard Penczewski's work on the Polish film Ida; 12-time nominee and digital pioneer Roger Deakins' work on Unbroken; and the eventual winner Emmanuel Lubezki for Birdman or (The Unexpected Virtue of Ignorance). The nominees indicate that the transition to digital was all but complete in that for the first time in the history of the award, 4 of the 5 nominees were shot digitally with only Yeoman shooting on $35 \mathrm{~mm}$ film. Perhaps because of this trend toward a total digital workflow, I read the cinematography nominees as advancing a neo-traditional discourse and as such an example of Caldwell's ATL rear-guard control schemes. The films shortlisted for the 2015 ceremony seemed to privilege an almost auto-referential approach with stakeholders eligible to vote in the cinematography category celebrating films that showcased classical techniques and that were in some way about a particular understanding of filmmaking itself. The nominated films all thematise appropriate aesthetic conduct, featuring characters that modestly craft a self-consciously pictorial look ostensibly over a real environment. This emphasis on artistic beauty gestures to its conditions of production, positioned in this instance as a commitment to traditional cinematographic practice over computer wizardry. 
Beauty here serves to consecrate the workflows that shape its realisation. In the following I argue that these post-digital control schemes are organised around two interlocking principles: nostalgia for neo-traditional craftsmanship (that would institutionalise aesthetic sensibility within the lineage of recognised professional communities) and shooting strategies (that would emphasise physical, on-set techniques that I call 'digital naturalism').

In a review of Mr. Turner, Peter Bradshaw comments on the film's representation of the eponymous pre-impressionist painter: 'It doesn't show him being tormented by self-doubt ... He is prosperous, confident, selfassured ... He's an artist who is at the peak of his profession, almost like a professional man, a craftsman' (Brooks et al, 2014). Timothy Spall's J.M.W. Turner is presented as embedded in a genealogy of respectful, old-school professionalism as is implicit in the film's title. Mr. Turner is less an anguished, solitary visionary, more a jobbing artisan anchored in his household workshop and surrounded by loyal, if under-appreciated, acolytes including his father (a former barber) and his housekeeper. Painting materials too are locally sourced including pigs' heads from the town butchers and pigments such as bladders of ultramarine and bottles of poppy oil from the neighbouring colourman's emporium of curios. Turner is also part of a broader professional network via his membership of the Royal Academy of Arts, a circle of rivaling co-dependents who bicker affectionately about light and colour. The film thus functions as a riposte to mythopoeic accounts of creativity operating in a vacuum and instead works to locate the production of art in traditional trade methods, craft communities and cottage industries. These humanist communities of workers and enthusiasts are contrasted in the film with mechanical, technocratic science as represented by the encroaching steam age. The film's reproduction of Turner's Rain, Steam and Speed: The Great Western Railway (1844) underscores the film's elegiac tone in implying that Turner's practice, anchored in familial, local and fraternal communities, is to be superseded by technological progress. No doubt these concerns would speak to the cinematographic community whose own long-standing set of practices and communities are similarly under threat. The film therefore performs a high-wire act in balancing Turner's extreme ordinariness with his undoubted artistic exceptionalism; an exceptionalism whose truth, despite all the modesty, is visible on the screen in cinematographer's Dick Pope's reproduction of Turner's aesthetic.

In this regard, the film's repudiation of technology points to the second ATL control scheme visible in the nominees in how discourses that circulate around the films position creative practice. There is a nostalgic trend here too that I call 'digital naturalism'. Apparently regretting and almost apologetic for the use of digital technology, the approach emphasises on-set procedures and organic materials, and hence traditional methods. In sympathy with this position, responses to Mr. Turner focused on the naturalistic look of Pope's compositions alongside the corporeality of Spall's performance. If, as Ariel Rogers has indicated, digital technology is positioned as disembodied, Turner's craft is 
alternatively presented as weighty and materialist (see Rogers, 2012). Creativity here is neither an intellectual idea nor a feat of technology. Instead, Turner's aesthetic is understood as a relationship to natural surroundings and hard-won through the senses. Spall's Turner grunts, spits and ejaculates his way through the film leaving a DNA signature of his body on his canvases. Concomitantly, Turner's use of naturally occurring materials and organic colour pigments implicitly afford the resulting images heft, authenticity and life. Indeed, art is seen to be co-extensive with Turner's bodily life force. The film is shot through with portents of Turner's own mortality viewed as coterminous with the passing of a way of life rooted in long-standing institutions and techniques. When a photographer who Turner visits claims, in a premonition of digital hubris, to have 'captured the rainbow', Turner responds, 'I fear I too am finished'. The implication is technology will annihilate the lovingly antiquated craft communities and embodied practices documented in the film. Similarly, Mr. Turner reproduces the inspiration for Turner's elegiac masterpiece The Fighting Temeraire (1838). When Turner encounters the warship, tugged now by a steamer, he comments, 'Going to her death I fear ... We're observing the future. The film's cinematographer Dick Pope echoes Turner in his own comments on shooting this scene. Pope reveals, 'The warship is CG, but everything else is real' (cited in Bergery, 2015, p. 68). The film can be read as an obituary to the superannuated practices of Turner and the traditional cinematographer. However, digital naturalism preserves these realistic traditions alongside judicious use of CGI, commemorating Turner's craft not only in the film's narrative but also in the look on the screen.

In The Grand Budapest Hotel these themes are extended in how the film remembers the hotel's concierge, Gustave. Continuing our elegiac motif, a character known only as 'The Author' reminisces about his previous visit to the hotel where he is told of its golden age under Gustave's stewardship. If the film's politics are a conservative appeal to the refined manners of yesteryear, then these qualities are actualised in the hotel's 'look', as sculpted by Gustave during its 1920s heyday. Gustave's fastidiousness constitutes a neo-traditional elegy for a lost world of precision and attention to detail, qualities seen to be under threat by the brutal philistinism of the modern age. It is not enough then that the nominated films be beautiful, they also must be shown to me made beautifully by devotees committed to beauty. If Turner is represented as the prototype 'painter with light', Gustave is the cinematographer of the Grand Budapest's look. Gustave artfully orchestrates delicate compositions from the meticulously designed chocolate box colour palette to the pleasingly balanced symmetries of the hotel's décor and table settings: a skillset that he passes on to his apprentice, Zero. Implicitly the skills are also passed onto the crew ultimately responsible for the film's look in the present. David Bordwell draws attention to formal signatures within director Wes Anderson's portfolio crafted alongside his frequent collaborator, cinematographer Robert Yeoman. These include planimetric compositions and an avoidance of deep staging that are 
consistent with Gustave's similar professional exactitude. Bordwell writes, 'The director's "dollhouse" shots yield cross sections ... Thanks to right angles, central perspectives, and symmetrical layouts, his carpented world gains a layer of formality, almost ceremony' (Bordwell, 2015, p. 238). Just as Gustave's ceremonial aesthetic belongs to a bygone era, Bordwell stresses the carpentry work done by the film's crew, again balancing artistry and traditional craftwork in a further example of neo-traditional digital naturalism. As reiterated by Yeoman:

Wes tried to plan out as much of the movie in advance as possible ... We plan our shots pretty carefully during prep. Occasionally, new ideas come up while we're shooting, but we generally have a pretty good idea of what to expect for each scene (cited in Stasukevich, 2014)

An origin myth is constructed to guard against subsequent tampering that might compromise the authors' original vision in the manner that, in the film, the hotel itself has fallen into disrepair following Gustave's death and the subsequent collapse of standards amongst the hotel's retinue. The impression is that the look of the film is authored in the pre-visualisation sequences, storyboarding and the production design, vouchsafing a traditionalist emphasis that is underscored by Yeoman's use of $35 \mathrm{~mm}$ film. As with $M r$. Turner, pictorial prettiness is not mere ornamentation; the film's politics are instead reducible to its mise-en-scène and the collaborative circle of followers dedicated to its realisation. Both the film's crew and the hotel's staff testify to a traditionalist dedication to aesthetic principles, seniority and an established workflow. The resulting beauty justifies an otherwise conservative and arbitrary division of labour. This 'natural order of things' is further ratified in the film by Gustave's membership of the Society of the Crossed Keys that positions him as following the time-honoured rules of a profession. Riffing on the motto of that other mysterious organisation, the ASC, if authority stems from dedication to traditional practice and workflows, it is an authority that can be safeguarded by exacting principles of 'art' and 'loyalty', if not exactly 'progress'.

Themes of art and loyalty to a vanishing way of life are also prominent in Pawel Pawlikowski's Ida that narrates the experiences of the eponymous young novitiate in Poland in the early 1960s. Before her vows, Ida is released from the convent to meet her aunt 'Red Wanda', a public prosecutor of the Stalinist era. A mournful road movie emerges whereby Poland's wartime anti-Semitic past is excavated as the pair search for the burial site of Ida's murdered Jewish parents. In the course of their journey the pair encounter emergent pop culture via a young hitchhiking saxophonist whose group plays 1960s Polish pop and American jazz. The film thus offers Ida compromised responses to the scorched earth of central European postwar experience. Wanda's apostate commitment to socialist ideology has exhausted itself in a retreat to alcoholism, promiscuity and eventually suicide, yet the representation of liberal individualism in the figures of the musicians seems empty and directionless. The film is more 
ambivalent regarding Ida's Catholicism. Religion in the film is presented less as a belief system and instead as a way of life orchestrated around a set of rituals, administered by a group of adherents and anchored in a particular place. Like Turner's workshop and Gustave's hotel, the convent offers something selfless and permanent that is abstracted from the violent experience of historical change. In contrast to individual extroverted flamboyance, the convent represents a sanctum of introspection where the self commits to contemplative, communal practice. This culminates towards the end of the film where one of Ida's fellow novices takes her vows, repeating the catechism, 'I vow chastity, poverty and obedience'. If $I d a$ is ultimately agnostic about institutionalised belief, like Mr. Turner and The Grand Budapest Hotel, it surrenders to the transcendent as represented in aesthetics. The truth of this alternative is self-evident in the beauty of the film's look on the screen that, as with the other nominees, threatens to overwhelm competing meanings in the film. Tellingly, many commentators regarded that the key to Ida's meaning was locked in an understanding of its enigmatic look. Representative here is David Denby's review in The New Yorker:

I can't recall a movie that makes such expressive use of silence and portraiture; from the beginning, I was thrown into a state of awe by the movie's fervent austerity ... Sometimes the figures are positioned at the bottom of the frame, with enormous gray Polish skies above them, as if the entire burden of a cursed country weighed on its people (Denby, 2014)

Denby's response seeks symbolic closure whereby the aesthetic ultimately references Polish history, yet his language suggests a less intellectual, more experiential and transcendent response. This alternative interpretation is consistent with the positioning of Pawlikowski's work as 'poetic realism'. As described by Claire Monk, "A "poetic" aesthetic is framed as a matter of auteurist "personal expression" and celebrated for its own sake as a desirable end in itself' (Monk, 2012, p. 486). Poetic realism locates meaning less in something as crude as history and more in artistry as a self-sacrificing testimony to itself. Perhaps of more interest than the meaning of the film's look is the very compulsion to seek meaning in this assertive beauty. Ida's aesthetic freezes narrative time into a rapturous state and focuses attention on the image's opaque density; its purely formal qualities. Accounts of Lukasz Zal's shooting strategy for Ida are in keeping with a sympathetic model of digital naturalism that similarly attempts to stop time:

Ida's form was designed to be as unadorned as possible. Almost all the shots are locked off ... There is no traditional coverage. Zal describes the approach as creating scenes with "posters" - wide, static frames that enclose the characters (Bergery, 2014, p. 57). 
'Unadornded' by layers, the craft here is stripped down to its essentials and cloistered from the ravages of progress. The static, wide-angle compositions, black-and-white aesthetic, the 1:33:1 aspect ratio alongside the absence of coverage serves to pull the film's aesthetic in the direction of still photography. The cinematography hauls the craft back to its origins in 'painting with light' and underscores the film's own retreat into ancient certainties. The look of Ida is ultimately its own sanctuary, where beauty rather than Polish history manifests the film's timeless answer to modernity. As with Mr. Turner and The Grand Budapest Hotel, Ida's politics are ultimately aesthetic: art is its own purpose and reward, inviting the viewer to seek refuge in its austere purity.

Birdman's protagonist is Riggan Thomson, an actor previously famous for his role in a superhero franchise who stakes his reputation on a theatrical adaptation of a Raymond Carver short story. In Birdman, art is again anchored in a community of (in this case cranky) professionals whose individual selfabsorptions ultimately dissolve in the successful execution of a collaborative aesthetic project. Alongside Ida's convent, Turner's workshop and Gustave's hotel, the physical space of Birdman's Broadway theatre is the crucible that allows the creative process to be organically realised in contrast to the implicitly CGI-showy mass culture represented by Riggan's previous career. If the antagonists of The Grand Budapest Hotel are those that do not respect craftsmanship, Mr. Turner is anxious to produce an anti-technological appeal to natural craftsmanship, and $I d a$ works to craft a compositional beauty that outdistances the temporal, Birdman celebrates a theatrical aesthetic. The central conceit of Birdman is the long take that reinforces the live-action immediacy of this theatricality. The long take is also the technique in the cinematographer's arsenal apparently least affected by the transition to the digital workflow. Accounts of the rise of the Steadicam, for instance, highlight how the technology in the words of Ramaeker might, 'replace the need for cutting' (Ramaeker, 2014, p. 120). Seemingly renouncing postproduction, Birdman's resulting digital naturalism testifies that events were filmed in real time by a real crew. The 'realism' of this long take is showily theatrical, however. As described by Peter Bradshaw, 'there's traditionally a fair bit of cinephile machismo involved in the continuous tracking shot ... No movie flourish draws attention to itself quite as emphatically as this' (Bradshaw, 2016). Accounts stress the labour-intensive techniques deployed by cinematographer Emmanuel Lubezki in principal photography, including practical lighting and Steadicam operation. American Cinematographer, for instance, points to the physicality of Lubezki's camera whirling through the sinewy passages of the set built by production designer Kevin Thompson:

The camera was in constant motion, executing dozens of 360-degree moves, with Lubezki following characters or pedaling backwards in front of them, scaling catwalks and descending to the stage (Oppenheimer, 2014, p. 57) 
If Ida's shooting strategy attempts to make time stand still, Birdman's attempts to make it run, or, better, fly. The result is not merely consistent with the setting of theatre with actors spontaneously improvising in motion but also with digital naturalism as a strategy for consolidating the cinematographer's centrality. The long take underlines the live athleticism of Lubezki's camera as an embodied fellow actor whereby cinematography itself becomes a theatrical performance to be noticed and acclaimed.

If one platform of the neo-traditional ATL narrative is the Oscar ceremony, another is the behind-the-scenes machination of the ASC. In 2002, the ASC president Steven Poster intensified the activities of its Technology Committee with a multi-million dollar research centre devoted to postproduction workflow (See Misek, 2010, p. 407, Lucas, 2014, p. 135). The fallout was felt in 2007 when the Technology Committee established a 'colour decision list' (CDL) described by Caldwell as a way to do digital production 'the film way' (2008, p. 184). The CDL lists the metadata recorded on set meaning that any subsequent alteration can be tracked and potentially regulated. Misek summarises the compromise: 'Cinematographers control the overall colour scheme of a film; colourists have control over more precise shot-by-shot colour effects' (2010, p. 408). All the same, the fallout of these upheavals continues to be felt in the anxiety surrounding authorship of the digital look. Alongside the ATL control schemes documented above are lower profile BTL counter-measures including leaks from digital production houses revealing their input into the final aesthetic of nominated films including Rhythm and Hues work on Life Of Pi (see p. 106, Life After Pi, 2014), the intensive grading of LOOK Effects on The Grand Budapest Hotel (see Wilson, 2014) and Rodeo FX team's work on stitching together the illusion of continuity in Birdman (see Fotheringham, 2015). It is perhaps not coincidental therefore that a final trope of the current discourse surrounding the digital look attempts to foreground management and supervision to discipline the workflow (see Lucas, 2014, p. 155). If my emphasis has been on a conservative account of the 'art' of the cinematographer as 'loyalty' to traditional communities, the films nominated in the 2015 awards are keen to also stress the cinematographer's management of the workflow's entire crew extending now into new arenas of digital postproduction and effectively acknowledging the compromise negotiated by the ASC. The nominee where the question of management of the digital team is perhaps most prominent is Roger Deakins' cinematography on the otherwise critically savaged Unbroken. I want to speculate that the unity of Deakins' management of the workflow is, in part, shored up by disavowing the input of a substitute newcomer who was still less part of the team than the digital effects workers. Accounts of Deakins's contribution stress his own seniority in comparison with the film's inexperienced director, Angelina Jolie. Jolie's celebrity, her association with CGI through appearances in Lara Croft: Tomb Raider (2001) and Beowulf (2007) and her femininity cast her not as an active 
rival, but as a passive screen onto which are projected narratives of masculine control. As Guy Lodge writes:

If any film-maker were to give Zamperini's a chance, it's not the green, humourless Jolie, who has a clear gift for choosing collaborators cinematographer Roger Deakins, the usually electric Jack O'Connell but can't marshall them for saccharine, amber-coloured coffee (Lodge, 2015)

The male crew is measured and venerated against the backdrop of Jolie's managerial incompetence. Into the vacuum steps the cinematographer-asmanager. Behind the scenes publicity shots positioned the young Jolie alongside Deakins as did American Cinematographer that stated, 'Standing by her side was Roger Deakins, ASC, BCS, whose presence undoubtedly inspired confidence' (Oppenheimer, 2015, p. 41). Deakins is represented as authoritative, professionally accredited and marshaling his team with aesthetic grace and managerial skill. It is apparent then that accounts were keen to exonerate Deakins from the film's problems and instead situate him as a reassuringly patrician figure who implicitly rescued Jolie from her own fledgling status by orchestrating his male team. As Deakins states, 'Our Australian crew was top-class: Shaun, Toby, AJ ... Brian Cox. They were all terrific - as were my regulars, Andy, Bruce and Josh' (cited in Oppenheimer, 2015, p. 53). The collaborative process now extends beyond principal photography and into the similarly masculine arena of postproduction. Deakins's regulars here include digital imaging technician Josh Gollish and digital colourist Mitch Paulson, now also within the fold of Deakins' management. As Deakins continues, 'We actually had quite a lot to do ... because of the number of visual - effects shots' (cited in Oppenheimer, 2015, p. 53). Ultimately, the discourse around the film asserts the cinematographer's authority over previously warring factions within the workflow with the director herself relegated to the margins. The newfound harmony under Deakins' management is, in part, a function of the 'green', 'saccharine' and female Jolie's expulsion that tightens the remaining circle of experience, aesthetic refinement and masculinity.

\section{Postscript: The cinematographer as revenant}

The Oscar ceremony of 2016 took place at the Dolby Theatre on 28 February. Whilst controversy swirled around the hashtag \#OscarsSoWhite, Emmanuel Lubezki would return to win his third consecutive best cinematography Oscar for a further collaboration with director Alejandro G. Iñárritu. The Revenant (2015) recounts the 'harrowing survival story' of Hugh Glass who awakens in a shallow grave following a ferocious attack from a CGI rendered grizzly bear 
and pursues the party of former colleagues that betrayed him. In a review for Vanity Fair, Richard Lawson describes the film as 'über-masculine' and a form of 'macho vérité. His review concludes:

Much hay will be made about The Revenant's white-knuckle gruesomeness, and I suspect many viewers will take pleasure in feeling ragged but a little tougher for having sat through this slow, torturous adventure. Which, I think, is the intended effect. (Imagine how tough everyone feels for making it.) (Lawson, 2015)

The Revenant follows the 2015 nominees in its symmetry between Glass's own engagement with the elements of the frontier and the crew's own digital naturalism experienced during the shoot in Canada. Michael Goldman's account in American Cinematographer also positions the film's internal narrative as an allegory for the filmmaking process stating 'the entire crew performed "as true filmmakers" - a hearty band of collaborators on their own adventure, mirroring the saga they were putting onscreen'. (Goldman, 2016, p. 28) His account is anxious to stress the direct, unmediated naturalism of the shoot that, whilst shot digitally on the Arri Alexa and Alexa Xt, exclusively used natural lighting, was shot in chronological order and, like DiCaprio's resourceful protagonist, had to deal with primal, elemental forces such as lenses contracting due to sudden drops in temperature. Lubezki himself speaks of the process:

We discovered that when you are exposed to the weather and these conditions every day, you have to adapt. I had to shoot the movie chronologically, because that is how it is written - it starts in autumn and moves into winter. And the character goes through a very real physical experience of being in the middle of nowhere for months. So we couldn't do it on a set, under normal Hollywood rules, and bring in snow and put in bluescreens. I wanted to absolutely kill any artifice. In keeping with that truth, we had to go through a true natural process (cited in Goldman, 2016, p. 38)

This unmediated naturalism would extend to the crew enlisting the Canadian authorities to trigger an actual avalanche using a helicopter that dropped explosive charges in coordination with Glass's reaction on the foreground as he realises the extent of his betrayal. The narrative hence recounts the importance of loyalty between hyper-competitive communities within brutal conditions apparently, at least, similar to the crew's experience described by Lubezki as 'the roughest and hardest thing I have ever done in my life' (cited in Goldman, 2016, p. 37). Goldman's account hence acknowledges the input of the apparently all-male crew consisting of production designer Jack Fisk, gaffer 
Martin Keough, digital imaging technician Arthur To, camera operator Scott Sakamoto and supervising finishing artist Steve Scott - described by Lubezki as 'my right hands' (cited in Goldman, 2016, p. 38). In short, The Revenant would recapitulate the major themes of the 2015 nominees including the ideology that a return to muscular methods in natural conditions can reinvigorate an aesthetic alongside the significance of loyalty and hierarchy within neo-traditional, homo-social working communities. As argued above, these Oscar nominees for best cinematography demonstrate an anxiety on behalf of the cinematography community to stress that the cinematographer is himself a revenant, and that despite attempts to kill him off he remains the key collaborator in the production of the film's look in the digital age. As such, the nominations can be read following Caldwell as an example of an ATL control scheme designed to reassert a neo-traditional workflow and division of labour that polices established professional and sometimes gender hierarchies. The films and the trade publicity circulating around their release work in tandem to recentralise the cinematographer as the dominant figure in the conception, management and execution of the look.

\section{References}

Atkinson, J. (2001). The Oscars: The Pocket Essentials. Harpenden: Pocket Essentials.

Beach, C. (2015). A Hidden History of Film Style: Cinematographers, Directors and the Collaborative Process, Oakland, CA: University of California Press.

Bergery, B. (2014). Divine purpose. American Cinematographer 95 (5): 54-64. . (2015). Eloquence through art. American Cinematographer 96 (1): 66-75.

Bordwell, D. (2015). Wes Anderson takes the 4:3 challenge. In Seitz, M. (Ed.). The Wes Anderson Collection: The Grand Budapest Hotel. New York, NY: Abrams pp. 235-51.

Bradshaw, P. (2016). Victoria Review - gripping one-take thriller on the streets of Berlin. Guardian. Retrieved from http://www.theguardian.com/ film/2016/mar/31/victoria-review-one-take-berlin-schipper-heist-thriller.

Brooks X. et al (2014). The Guardian Film Show: Mr Turner, Nightcrawler, The Overnighters and Horns - video reviews. Guardian. Retrieved from http:// www.theguardian.com/film/video/2014/oct/31/mr-turner-nightcrawlerthe-overnighters-horns-video-reviews.

Buckley, C. A statue more than worth its weight in gold: Measuring the effects of Oscar nods and wins. Newyorktimes.com, 3 December. Retrieved from https:/www.nytimes.com/2014/12/04/movies/awardsseason/measuringthe-effects-of-oscar-nods-and-wins.html?_r=0

Caldwell, J. (2008). Production Culture: Industrial Reflexivity and Critical Practice in Film and Television, Durham, NC: Duke University Press. 
. (2013). Authorship below-the-Line. In J. Gray and D. Johnson (Eds) A Companion to Media Authorship, Somerset, NJ: John Wiley and Sons, pp. 349-69.

. (2014). Para-industry, shadow academy, Cultural Studies, 28 (4): 720-40.

Coleman, L. (ed.) (2016). Transnational Cinematography Studies, Lanham, MD: Lexington Books.

Corrigan, T. (1990). The commerce of auteurism: A voice without authority. New German Critique, 1 (49): 43-57.

Cowan, P. (2012). Underexposed: The neglected art of the cinematographer. Journal of Media Practice, 13 (1): 75-96

Curtin, M. \& Vanderhoef, J. (2015). A vanishing piece of the Pi: The globalization of visual effects labor. Television and New Media, 16 (3): 219-39.

Denby, D. (2014). "Ida": A Film Masterpiece. New Yorker. Retrieved from http://www.newyorker.com/culture/culture-desk/ida-a-film-masterpiece.

Fotheringham, S. (2015). The use of VFX to stitch Birdman together. BTLNews. Retrieved from http://www.btlnews.com/awards/the-use-of-vfx-to-stitchbirdman-together.

Florida, Richard. (2012). The Rise of the Creative Class: Revisited, Revised and Expanded, New York: Basic Books.

Gaskin, S. (2013). Christopher Doyle interview part 2: "Life of Pi" Oscar is an insult to cinematography. Retrieved from http://sea.blouinartinfo.com/ news/story/874483/christopher-doyle-interview-part-2-life-of-pi-oscar-isan.

Gehrlein, W. and Kher, H. (2004). Decision rules for the Academy Awards versus those for elections. Interfaces 34 (3): 226-34.

Gerstner, D. and Staiger, J. (Ed.) (2003). Authorship and Film, London and New York: Routledge.

Goldman, M. (2016). Left for dead. American Cinematographer, 97 (1): 36-53

Goodale, G. (2004). Oscar winners reflect on getting gold. The Christian Science Monitor Retrieved from http://www.csmonitor.com/2004/0227/p11s02almo.html.

Keating, P. (2010). Hollywood Lighting from the Silent Era to Film Noir, New York, NY: Columbia University Press.

Lawson, R. (2015). The Revenant is a harrowing survival story that strains for meaning. Vanity Fair. Retrieved from http://www.vanityfair.com/ hollywood/2015/12/the-revenant-review-leonardo-dicaprio.

Lodge, G. (2015). DVDs and downloads: Birdman, Unbroken, The Last Five Years and more. Guardian. Retrieved from http://www.theguardian.com/ film/2015/may/03/birdman-unbroken-the-last-five-years-dvd-review-guylodge.

Lucas, C. (2014). The Modern Entertainment Marketplace, 2000-present. In P. Keating (Ed.) Cinematography (Behind the Silver Screen), New Brunswick, NJ: Rutgers University Press, pp. 132-57. 
McRobbie, A (2016). Be Creative: Making a Living in the New Culture Industries, London and Malden, MA: Polity Press.

Misek, R. (2010). The 'look' and how to keep it: Cinematography, postproduction and digital colour. Screen, 15 (4): 404-9.

Monk, C. (2012) 'If you can't make a good political film, don't': Pawel Pawlikowski's resistant poetic realism. Journal of British Cinema and Television, 9 (3), pp. 480-501

Oppenheimer, J. (2014). Backstage drama. American Cinematographer, 95 (12): $54-67$.

. (2015). Ultimate survivor. American Cinematographer, 96 (1): 40-53.

Prince, S. (2004). The emergence of filmic artifacts: Cinema and cinematography in the digital era. Film Quarterly, 57 (3): 24-33.

Ramaeker, P. (2014). The New Hollywood: 1981-1999. In P. Keating (ed.) Cinematography (Behind the Silver Screen), New Brunswick, NJ: Rutgers University Press, pp. 106-31.

Rogers, A. (2012). "You Don't So Much Watch It As Download It": Conceptualizations of digital spectatorship. Film History, 24: 221-34.

Ross, A. (2004). No-Collar: The Humane Workplace and its Hidden Costs, Philadelphia, PA: Basic Books.

Stahl, M. (2009). Privilege and distinction in production worlds: Copyright, collective bargaining and working conditions in media making. In Mayer, V., Banks, M. Caldwell, J. (Eds) Production Studies: Cultural Studies of Media Industries, New York: Routledge, pp. 132-57.

Stasukevich, I. (2014). 5 star service. American Cinematographer, 95 (3): 30-41. Wexman, V. (ed.) (2003). Film and Authorship. New Brunswick, NJ: Rutgers University Press.

Wilson, T. (2014). A distinctive look for 'The Grand Budapest Hotel'. Retrieved from https://library.creativecow.net/wilson_tim/VFX_The-Grand-BudapestHotel/1. 
